\title{
Obese individuals experience wheezing without asthma but not asthma without wheezing: a Mendelian randomisation study of 85437 adults from the Copenhagen General Population Study
}

\author{
Yunus Çolak, ${ }^{1,2,3,4}$ Shoaib Afzal, $^{3,4,5}$ Peter Lange, 2,3,4,5,6 Børge G Nordestgaard ${ }^{3,4,5}$
}

- Additional material is published online only. To view this file please visit the journal online (http://dx.doi.org/10. 1136/thoraxjnl-2015-207379)

For numbered affiliations see end of article.

\section{Correspondence to} Professor Børge $G$ Nordestgaard, Department of Clinical Biochemistry, Herlev and Gentofte Hospital, Copenhagen University Hospital, Herlev Ringvej 75, Herlev DK-2730, Denmark; Boerge.Nordestgaard@regionh. $\mathrm{dk}$

Received 4 June 2015 Revised 17 August 2015 Accepted 9 September 2015 Published Online First 26 October 2015

\section{SLinked}

- http://dx.doi.org/10.1136/ thoraxjnl-2015-207662

CrossMark

To cite: Çolak Y, Afzal S, Lange $P$, et al. Thorax 2016;71:247-254.

\section{ABSTRACT}

Background Observational studies suggest that obesity is associated with increased risk of asthma. However, it is unknown whether this could be explained by wheezing. We tested the hypothesis that high body mass index (BMI) observationally and genetically is associated with high risk of wheezing and asthma, and that the association between high BMI and asthma is explained by wheezing.

Methods We genotyped 85437 individuals aged 20-100 years from the Copenhagen General Population Study for FTO (rs9939609), MC4R (rs17782313), TMEM18 (rs6548238) GNPDA2 (rs10938397) and BDNF (rs 10767664); 14500 individuals experienced wheezing and 5406 had asthma. Wheezing was selfreported, and asthma was ascertained through selfreport, hospital contacts with asthma, and/or receiving medication for asthma. BMI was calculated as measured weight divided by measured height squared $\left(\mathrm{kg} / \mathrm{m}^{2}\right)$.

Results In observational analyses versus BMl of 18.5$22.4 \mathrm{~kg} / \mathrm{m}^{2}$, ORs for wheezing were $1.23(95 \% \mathrm{Cl} 1.00$ to 1.52) for $\mathrm{BMl}<18.5 \mathrm{~kg} / \mathrm{m}^{2}, 1.17$ (1.10 to 1.25$)$ for $22.5-$ $24.9 \mathrm{~kg} / \mathrm{m}^{2}, 1.44(1.35$ to 1.54$)$ for $25-27.4 \mathrm{~kg} / \mathrm{m}^{2}, 1.86$ (1.73 to 1.99 ) for $27.5-29.9 \mathrm{~kg} / \mathrm{m}^{2}, 2.48$ (2.31 to 2.66 ) for $30-34.9 \mathrm{~kg} / \mathrm{m}^{2}, 3.86$ (3.48 to 4.28 ) for $35-$ $39.9 \mathrm{~kg} / \mathrm{m}^{2}$ and 6.05 (5.12 to 7.14 ) for $\mathrm{BMl} \geq 40 \mathrm{~kg} / \mathrm{m}^{2}$. Corresponding ORs for asthma were 1.28 (0.95 to 1.74$)$, 1.07 (0.97 to 1.17$), 1.14$ (1.04 to 1.25$), 1.32$ (1.20 to $1.46), 1.39$ (1.25 to 1.54$), 1.54$ (1.31 to 1.81 ) and 1.99 (1.55 to 2.56), respectively. Compared with BMl allele score $0-4$, scores 5,6 and $7-10$ were associated with $0.22,0.51$ and $0.76 \mathrm{~kg} / \mathrm{m}^{2}$ higher BMI, respectively. Genetically determined ORs per unit higher BMI were 1.22 (1.15 to 1.31) for wheezing, 1.18 (1.10 to 1.27 ) for wheezing without asthma, 1.08 (0.98 to 1.19) for asthma, and 0.85 (0.73 to 0.99 ) for asthma without wheezing. Corresponding observational ORs were 1.09 (1.09 to 1.10), 1.09 (1.08 to 1.09$), 1.03$ (1.03 to 1.04 ) and 0.99 (0.98 to 1.00 ), respectively.

Conclusions High BMI was associated with high risk of wheezing without asthma, but not with high risk of asthma without wheezing.

\section{INTRODUCTION}

Observational studies suggest that obesity is associated with increased risk of asthma, ${ }^{1-13}$ although there have been contradictory findings. ${ }^{3}$ 14-16 Importantly, asthma can lead to physical inactivity

\section{Key messages}

What is the key question?

- Is high body mass index (BMI) observationally and genetically associated with asthma and wheezing, and is the association between high $\mathrm{BMI}$ and asthma explained by wheezing.

\section{What is the bottom line?}

- High BMI is associated with high risk of wheezing without asthma, but not with high risk of asthma without wheezing. In the future, doctors should be hesitant to prescribe anti-inflammatory asthma medication to obese individuals only because they wheeze.

\section{Why read on?}

- This is the first study to assess obesity as a potential causal risk factor in the development of asthma and wheezing using genetics.

which may lead to weight gain. Furthermore, obese individuals often wheeze, ${ }^{10} 17$ which could bias the association with asthma as wheezing also is a cardinal symptom of asthma. Thus, it is uncertain whether obesity causes asthma or whether the association is due to reverse causation and/or confounding.

Although randomised, double-blind, placebocontrolled clinical trials often are considered the gold standard in establishing causal relationships, some exposures like tobacco smoking, alcohol intake and obesity would be unethical or impractical to study in such a study design. Another limitation of randomised clinical trials includes, if there exists a long lead time between the exposure and development of disease, for example, obesity as a risk factor in development of asthma, as such studies would require unattainable economical resources. An alternative approach not prone to reverse causation and largely free of confounding is that of Mendelian randomisation, using genetic variants as proxies of modifiable exposures. ${ }^{18}$ Thus, genetic variants that specifically associate with lifelong high body mass index (BMI) provide an ideal design to assess consequences of obesity, independent of other risk factors. ${ }^{19}$ We here use genetic variation in FTO (rs9939609), MC4R 
(rs17782313), TMEM18 (rs6548238), GNPDA2 (rs10938397) and BDNF (rs10767664), known to have the largest effect on $\mathrm{BMI},{ }^{20}$ to assess obesity as a potential causal risk factor in the development of asthma.

We tested the hypothesis that high BMI observationally and genetically is associated with wheezing and asthma, and that the association between high BMI and asthma is explained by wheezing. For this purpose, we used the Copenhagen General Population Study (CGPS) with 85437 individuals, of which 14500 experienced wheezing and 5406 had asthma. First, we investigated whether BMI was associated with wheezing and asthma (step 1, figure 1). Second and third, we investigated whether the genetic variants were associated with BMI and with wheezing and asthma (steps 2 and 3, figure 1). Finally, we investigated whether the genetic variants were associated with wheezing and asthma consistent with their association with high BMI using instrumental variable analyses (step 4, figure 1).

\section{METHODS}

\section{Participants}

We included participants from CGPS, initiated in 2003 with ongoing enrolment. ${ }^{21}$ Individuals aged $20-100$ years were randomly selected from the national Danish Civil Registration System to reflect the adult, white Danish population. All participants completed a comprehensive questionnaire, underwent a physical examination, and gave blood for biochemical and genetic analyses. Questionnaires were reviewed at the day of attendance by an investigator. At the time of genotyping, we had 85437 individuals available. All participants were white and of Danish descent as recorded in the national Danish Civil Registration System. The study was conducted according to the Declaration of Helsinki.

\section{Body mass index}

Weight $(\mathrm{kg})$ and height $(\mathrm{m})$ were measured at the day of attendance by an investigator with one decimal, blinded to information on wheezing, asthma and genotype. BMI was calculated as weight divided by height squared $\left(\mathrm{kg} / \mathrm{m}^{2}\right)$, and categorised similar to WHO: $<18.5 \mathrm{~kg} / \mathrm{m}^{2}, 18.5-22.4 \mathrm{~kg} / \mathrm{m}^{2}, 22.5-24.9$ $\mathrm{kg} / \mathrm{m}^{2}, \quad 25-27.4 \mathrm{~kg} / \mathrm{m}^{2}, \quad 27.5-29.9 \mathrm{~kg} / \mathrm{m}^{2}, \quad 30-34.9 \mathrm{~kg} / \mathrm{m}^{2}$,

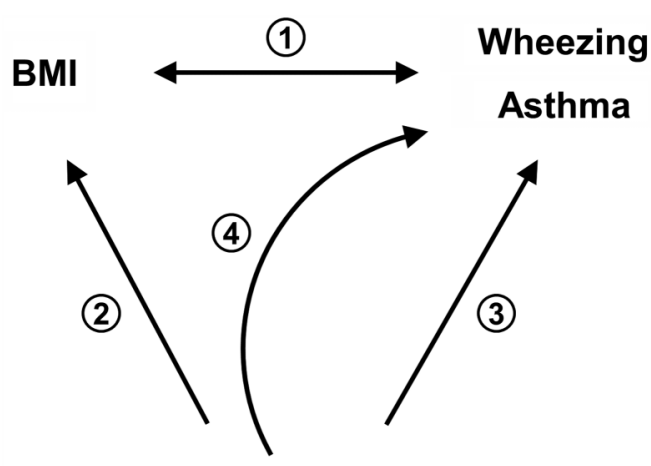

\section{BMI allele score}

Figure 1 Mendelian randomisation design in four steps. (1) Observational analyses suggest an association between BMI $\left(\mathrm{kg} / \mathrm{m}^{2}\right)$ and wheezing and asthma with uncertainty regarding the direction of causation and limited information on possible confounders; (2) The association of BMI allele score with BMI; (3) The association of the BMI allele score with wheezing and asthma; (4) Determining if BMI is potentially causally related to wheezing and asthma by using BMI allele score as an instrumental variable. BMI, body mass index.
$35-39.9 \mathrm{~kg} / \mathrm{m}^{2}$ and $\geq 40 \mathrm{~kg} / \mathrm{m}^{2} .22$ BMI of $18.5-22.4 \mathrm{~kg} / \mathrm{m}^{2}$ was chosen as reference in the statistical analyses; obese individuals were those with $\mathrm{BMI} \geq 30 \mathrm{~kg} / \mathrm{m}^{2}$.

\section{Genotyping}

Genotyping was conducted blind to information on BMI, wheezing and asthma. The ABI PRISM 7900HT Sequence Detection System (Applied Biosystems) was used to genotype FTO (rs9939609), MC4R (rs17782313), TMEM18 (rs6548238), GNPDA2 (rs10938397) and BDNF (rs10767664) with TaqMan assays; we chose the genetic polymorphisms known to have the largest effect on BMI. ${ }^{20}$ Genotyping was verified by DNA sequencing. As we performed reruns twice, call rates were above $99.8 \%$.

An aggregate instrument for BMI was created by constructing a score of $0-10$ based on the number of alleles associated with high BMI across the five genotypes, as done previously. ${ }^{21}$ Allele score was categorised into $0-4$ alleles $(n=23$ 937), 5 alleles $(n=23351), 6$ alleles $(n=21338)$ and $7-10$ alleles $(n=16811)$, to achieve a large number of individuals in the groups and thus high statistical power.

\section{Potential confounders}

Information on potential confounders was acquired from the questionnaires and reviewed at the day of attendance by an investigator. Familial predisposition for asthma was defined as at least one first degree relative (father, mother and/or sibling) with asthma. Smoking status was categorised as never, former or current smokers. Cumulative tobacco consumption was defined as tobacco consumed through smoking and measured in pack years based on information on duration of tobacco smoking and current amount of tobacco consumed. Education was based on years attending school and categorised as $<10$ years, 10-12 years and $\geq 13$ years. Annual household income was reported as $<$ Danish kroner (Kr)200 000, Kr200 000-400 000, Kr400 000$600000, \operatorname{Kr} 600000-800000$ and $\geq \operatorname{Kr} 800000$. Degree of physical activity in leisure time was reported as none or light activity $<2 \mathrm{~h} /$ week, light activity $2-4 \mathrm{~h} /$ week, light activity $>4 \mathrm{~h}$ or heavy activity $2-4 \mathrm{~h} /$ week, and heavy activity $>4 \mathrm{~h}$ or regular exercises per week. Degree of physical activity during work was reported as sitting, sitting/standing/sometimes walking, walking/ sometimes lifting, hard body work and retired/unemployed. Dietary intakes, including fast food, fruits and vegetables, were reported as number of intakes per day or week.

\section{Outcomes and measures}

Wheezing was defined as an affirmative response to the question: 'Do you occasionally have whistling or wheezing while breathing?' acquired from the questionnaire and reviewed at the day of attendance by an investigator.

Asthma was defined in four different ways: (1) Self-reported asthma: if participants responded affirmative to the question: 'Do you have asthma?' acquired from the questionnaire and reviewed at the day of attendance by an investigator; (2) Hospital contacts with asthma: if participants had an official doctor diagnosis of asthma, inpatient or outpatient (ICD8: 493 and ICD10: J45-J46) from 1977 until the day of attendance; (3) Receiving medication for asthma: if participants were neversmokers and responded affirmative to the question: 'Do you take medication for asthma/bronchitis (including sprays/dry powders)?' acquired from the questionnaire and reviewed at the day of attendance by an investigator; and (4) Any asthma: if participants were positive for one or more of the above definitions of asthma. Any participant who had hospital contacts with COPD (ICD8: 491-492 and ICD10: J41-J44) from 1977 until 
the day of attendance was excluded as an asthma case. Information regarding hospital contacts was obtained from the national Danish Patient Registry, covering all public and private Danish hospitals from 1977 until April 2013; we did not lose track of a single person during this period.

\section{Statistical analyses}

Deviation from the Hardy-Weinberg equilibrium with $\chi^{2}$ tests was investigated to assess the frequency of allele distribution across the five genotypes; deviation may suggest genotyping or population sampling errors. We included age, sex, familial predisposition for asthma, smoking status, cumulative tobacco consumption, education, annual household income, physical activity in leisure time and during work, and dietary intakes, including fast food, fruits and vegetables, as potential confounders in observational analyses, as these may associate with BMI, wheezing and/or asthma. Age at the day of attendance of the participants was used in the statistical analyses. Some participants lacked information on some of these covariates, and we, therefore, performed multivariate imputation using chained equations to fill out the missing values (see online supplementary table S1); however, without imputation results were similar, that is, after excluding individuals with missing values. Cuzick's non-parametrical trend test was used to assess trend across BMI categories and allele scores. Comparison of participants with and without wheezing or asthma was determined using Wilcoxon's non-parametrical rank-sum test for continuous data and Pearson's $\chi^{2}$ test for categorical data.

Association of observational BMI and genetic risk score for BMI (allele score) with wheezing and asthma was investigated using logistic regression (steps 1 and 3, figure 1). Association of allele score with BMI was estimated using multiple linear regressions with age and sex as covariates (step 2, figure 1). Finally, we investigated whether genetic high BMI was associated with wheezing and asthma by using the unweighted allele score in instrumental variable analyses, using the control function estimator in two stages (step 4, figure 1). ${ }^{19}{ }^{23}$ For the control function estimator, we used the predicted values and residuals from the first-stage linear regression as variables in the second-stage logistic regression to investigate the association with wheezing and asthma. SEs were estimated using sandwich estimators. We used a generalised Hausman specification test to compare the instrumental variable analysis estimates with the observational estimates. The null hypothesis is that the observational estimator is an efficient and consistent estimator of the true parameters. If this is the case, there should be no systematic difference between the two estimators. We evaluated the strength of the instrumental variable by examining the F-statistic from the first-stage regression: $F>10$ indicates sufficient strength to ensure statistical reliability of the instrumental variable estimates. ${ }^{19}$ The Wald test was used to assess interaction of BMI and sex on risk of wheezing and asthma, as sex differences have been suggested. ${ }^{13}$

All statistical analyses were performed using STATA/SE V.13.0 for Windows (StataCorp, College Station, Texas, USA).

\section{RESULTS}

Among 85437 individuals from CGPS, all of whom had all information available including genotypes, 14500 experienced wheezing (17\%) and 5406 had asthma (6\%); asthma was defined as self-reported asthma, hospital contacts with asthma and/or receiving medication for asthma (see online supplementary figure S1). BMI, wheezing and asthma were associated with almost all of the potential confounders (see table 1 and online supplementary table S2). However, BMI allele score was not associated with measured potential confounders (see table 1 and online supplementary table S3). Thus, BMI allele score can be used as a proxy for obesity and the association of obesity with wheezing and asthma can be studied largely free of confounding and without reverse causation as genotypes are present at birth. All genotypes were in Hardy-Weinberg equilibrium. Although individuals had a higher age on average, no differences could be observed according to the BMI allele score (table 1 and online supplementary table S3).

\section{$\mathrm{BMI}$ and risk of wheezing and asthma: observational estimates}

High BMI compared with BMI of $18.5-22.4 \mathrm{~kg} / \mathrm{m}^{2}$ was associated with high risk of wheezing and asthma, including selfreported asthma, hospital contacts with asthma, receiving medication for asthma and any asthma, in a dose-dependent manner when adjusting for potential confounders (see figure 2 and online supplementary figures S2 and S3). The ORs for wheezing were $1.23(95 \%$ CI 1.00 to 1.52$)$ for BMI $<18.5 \mathrm{~kg} / \mathrm{m}^{2}, 1.17$ (1.10 to 1.25 ) for $22.5-24.9 \mathrm{~kg} / \mathrm{m}^{2}, 1.44$ (1.35 to 1.54$)$ for $25-27.4 \mathrm{~kg} / \mathrm{m}^{2}, 1.86$ (1.73 to 1.99$)$ for $27.5-29.9 \mathrm{~kg} / \mathrm{m}^{2}, 2.48$ (2.31 to 2.66) for $30-34.9 \mathrm{~kg} / \mathrm{m}^{2}, 3.86$ (3.48 to 4.28 ) for $35-39.9 \mathrm{~kg} / \mathrm{m}^{2}$ and 6.05 (5.12 to 7.14 ) for BMI $\geq 40 \mathrm{~kg} / \mathrm{m}^{2}$ ( $\mathrm{p}$ for trend $<1 \times 10^{-300}$ ). Corresponding ORs for any asthma were 1.28 (0.95 to 1.74 ), 1.07 (0.97 to 1.17 ), 1.14 (1.04 to $1.25), 1.32$ (1.20 to 1.46$), 1.39$ (1.25 to 1.54$), 1.54$ (1.31 to 1.81 ) and 1.99 (1.55 to 2.56 ) ( $\mathrm{p}$ for trend $=8 \times 10^{-20}$ ), respectively. High BMI was also associated with high risk of wheezing without asthma, but not with asthma without wheezing (figure 2). Corresponding ORs for wheezing without any asthma were 1.19 (0.94 to 1.50$), 1.15$ (1.07 to 1.24$), 1.40$ (1.30 to 1.51 ), 1.83 (1.70 to 1.98$), 2.49$ (2.30 to 2.69 ), 3.77 ( 3.37 to 4.22 ) and 5.77 (4.85 to 6.87) ( $\mathrm{p}$ for trend $=2 \times 10^{-255}$ ), and for any asthma without wheezing 1.22 (0.80 to 1.86$), 0.94$ (0.83 to 1.07 ), 0.87 (0.76 to 0.99 ), 1.00 (0.87 to 1.16 ), 0.93 (0.79 to 1.08$), 0.64$ (0.47 to 0.88 ) and 0.90 (0.56 to 1.44 ) ( $\mathrm{p}$ for trend $=0.15$ ), respectively. There was no evidence of sex difference in risk of wheezing as a function of BMI ( $p$ for interaction $=0.99$ ); however, the association of BMI with any asthma was driven by women and did not exist for men ( $p$ for interaction $=0.001$ ) (see online supplementary figure $S 4)$.

\section{BMI allele score and BMI}

Compared with BMI allele score $0-4$, allele score 5 was associated with $0.22 \mathrm{~kg} / \mathrm{m}^{2}$ (95\% CI 0.15 to 0.30 ) higher BMI ( $0.9 \%$ higher), allele score 6 with $0.51 \mathrm{~kg} / \mathrm{m}^{2}$ (0.43 to 0.58 ) higher BMI (1.9\% higher) and allele score 7-10 was associated with $0.76 \mathrm{~kg} / \mathrm{m}^{2}$ (0.68 to 0.84 ) higher BMI (2.9\% higher) (figure 3). The genetic variants explained $0.43 \%$ of the variation in BMI. The individual genotypes (FTO, MC4R, TMEM18, GNPDA2 and BDNF) were each associated with higher BMI (see online supplementary figure S5).

\section{BMI allele score and risk of wheezing and asthma: genetic estimates}

High BMI allele score compared with BMI allele score of $0-4$ was associated with high risk of wheezing in a dose-dependent manner, but not with asthma, including self-reported asthma, hospital contacts with asthma, receiving medication for asthma and any asthma (see figure 3 and online supplementary figure S6). Compared with allele score 0-4, ORs for wheezing and for wheezing without any asthma were 1.05 (95\% CI 1.00 to 1.11$)$ and 1.06 (1.00 to 1.12 ) for allele score $5,1.10$ (1.04 to 1.15 ) and 1.07 (1.01 to 1.13 ) for allele score 6 , and 1.18 (1.12 to 
Table 1 Characteristics of participants in the Copenhagen General Population Study according to body mass index categories at examination

\begin{tabular}{|c|c|c|c|c|c|c|c|c|c|c|}
\hline & \multicolumn{9}{|c|}{ Body mass index $\left(\mathrm{kg} / \mathrm{m}^{2}\right)$} & \multirow{2}{*}{$\begin{array}{l}\text { Allele } \\
\text { score } \\
\mathrm{p} \text { for } \\
\text { trend }\end{array}$} \\
\hline & $\begin{array}{l}<18.5 \\
(\mathrm{n}=705)\end{array}$ & $\begin{array}{l}18.5-22.4 \\
(n=14842)\end{array}$ & $\begin{array}{l}22.5-24.9 \\
(n=21713)\end{array}$ & $\begin{array}{l}25-27.4 \\
(n=20581)\end{array}$ & $\begin{array}{l}27.5-29.9 \\
(n=13724)\end{array}$ & $\begin{array}{l}30-34.9 \\
(n=10783)\end{array}$ & $\begin{array}{l}35-39.9 \\
(n=2397)\end{array}$ & $\begin{array}{l}\geq 40 \\
(n=692)\end{array}$ & $\begin{array}{l}p \text { for } \\
\text { trend* }\end{array}$ & \\
\hline Age (years) & $58(46-68)$ & $54(45-65)$ & $57(47-66)$ & $59(49-68)$ & $60(50-68)$ & $60(51-68)$ & $59(49-67)$ & $57(48-65)$ & $8 \times 10^{-212}$ & 0.98 \\
\hline Men $(\%)$ & 12 & 23 & 42 & 55 & 57 & 52 & 38 & 30 & $<1 \times 10^{-300}$ & 0.91 \\
\hline Familial predisposition for asthma (\%) & 14 & 18 & 17 & 17 & 18 & 19 & 20 & 22 & $1 \times 10^{-8}$ & $0.004 \ddagger$ \\
\hline Ever-smokers (\%) & 55 & 53 & 57 & 60 & 61 & 61 & 61 & 57 & $2 \times 10^{-43}$ & $0.004 \ddagger$ \\
\hline $\begin{array}{l}\text { Cumulative tobacco consumption } \\
\text { (pack-years) } \dagger\end{array}$ & $20(7-33)$ & $12(4-25)$ & $14(5-28)$ & $16(7-30)$ & $20(8-34)$ & $21(10-36)$ & $20(9-37)$ & $19(7-35)$ & $6 \times 10^{-247}$ & $0.03 \ddagger$ \\
\hline Low level of education (\%) & 21 & 17 & 21 & 26 & 32 & 37 & 38 & 37 & $<1 \times 10^{-300}$ & 0.09 \\
\hline Low annual household income (\%) & 19 & 11 & 11 & 12 & 14 & 17 & 20 & 21 & $7 \times 10^{-77}$ & 0.10 \\
\hline Low physical activity in leisure time (\%) & 7 & 4 & 4 & 5 & 7 & 10 & 18 & 25 & $2 \times 10^{-248}$ & 0.34 \\
\hline Low physical activity during work (\%) & 26 & 32 & 32 & 30 & 28 & 25 & 25 & 28 & $3 \times 10^{-51}$ & 0.14 \\
\hline $\begin{array}{l}\text { Low physical activity in leisure time and } \\
\text { during work }(\%)\end{array}$ & 32 & 24 & 25 & 27 & 31 & 36 & 42 & 47 & $1 \times 10^{-180}$ & 0.74 \\
\hline Weekly intake of fast food (\%) & 22 & 24 & 24 & 25 & 25 & 25 & 26 & 32 & 0.001 & 0.95 \\
\hline Low intake of fruits $(\%)$ & 30 & 24 & 26 & 29 & 32 & 32 & 32 & 28 & $8 \times 10^{-63}$ & 0.08 \\
\hline Low intake of vegetables (\%) & 29 & 23 & 26 & 31 & 35 & 39 & 40 & 40 & $1 \times 10^{-250}$ & 0.07 \\
\hline Low intake of fruits and vegetables (\%) & 17 & 12 & 14 & 17 & 19 & 21 & 22 & 20 & $5 \times 10^{-112}$ & $0.03 \ddagger$ \\
\hline
\end{tabular}

Data are summarised as median with the 25 th and 75 th centiles, or per cent.

*p Values were calculated using Cuzick's non-parametrical trend test across ordered groups.

tOnly current and former smokers were included.

$\neq p$ Value non-significant when adjusted for number of individual trend analyses according to the Bonferroni method. 
Participants Events

\begin{tabular}{l}
\hline Wheezing \\
$B M I\left(\mathrm{~kg} / \mathrm{m}^{2}\right)$ \\
$<18.5$ \\
$18.5-22.4$ \\
$22.5-24.9$ \\
$25-27.4$ \\
$27.5-29.9$ \\
$30-34.9$ \\
$35-39.9$ \\
$\geq 40$
\end{tabular}

Wheezing without any asthma $B M I\left(\mathrm{~kg} / \mathrm{m}^{2}\right)$

$<18.5$

18.5-22.4

22.5-24.9

$25-27.4$

27.5-29.9

30-34.9

$35-39.9$

$\geq 40$

Any asthma

$B M l\left(k g / m^{2}\right)$

$<18.5$

$18.5-22.4$

22.5-24.9

$25-27.4$

$27.5-29.9$

30-34.9

$35-39.9$

$\geq 40$

Any asthma without wheeze

$B M I\left(k g / m^{2}\right)$

$<18.5$

18.5-22.4

22.5-24.9

25-27.4

27.5-29.9

30-34.9

$35-39.9$

$\geq 40$

$\begin{array}{cc}705 & 124 \\ 14,842 & 1,801 \\ 21,713 & 2,849 \\ 20,581 & 3,180 \\ 13,724 & 2,659 \\ 10,783 & 2,714 \\ 2,397 & 853 \\ 692 & 320\end{array}$

705

14,842

21,713

20,581

13,724

10,783

2,397

692

705
14,842
21,713
20,581
13,724
10,783
2,397
692


705
14,842
21,713
20,581
13,724
10,783
2,397
692

275

45
19
OR $(95 \% \mathrm{Cl})$

P for trend

124
1,801
2,849
3,180
2,659
2,714
853
320

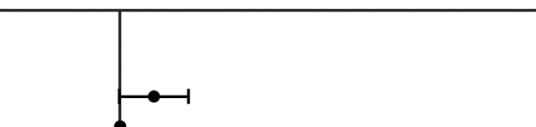

$1.23(1.00-1.52)$

1.0

$1.17(1.10-1.25)$

$1.44(1.35-1.54)$

$1.86(1.73-1.99)\}<1 \cdot 10^{-300}$

$2.48(2.31-2.66)$

$3.86(3.48-4.28)$

$6.05(5.12-7.14)$

$\left.\begin{array}{l}1.19(0.94-1.50) \\ 1.0 \\ 1.15(1.07-1.24) \\ 1.40(1.30-1.51) \\ 1.83(1.70-1.98) \\ 2.49(2.30-2.69) \\ 3.77(3.37-4.22) \\ 5.77(4.85-6.87)\end{array}\right\} \quad 2 \cdot 10^{-255}$

$\left.\begin{array}{c}1.28(0.95-1.74) \\ 1.0 \\ 1.07(0.97-1.17) \\ 1.14(1.04-1.25) \\ 1.32(1.20-1.46) \\ 1.39(1.25-1.54) \\ 1.54(1.31-1.81) \\ 1.99(1.55-2.56)\end{array}\right\} \quad 8 \cdot 10^{-20}$

$1.22(0.80-1.86)$

1.0

$0.94(0.83-1.07)$

$0.87(0.76-0.99)$

$1.00(0.87-1.16)$

$0.93(0.79-1.08)$

$0.64(0.47-0.88)$

$0.90(0.56-1.44)$

0.15

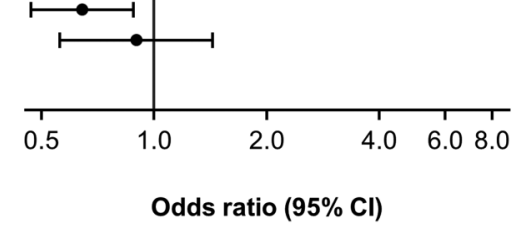

Figure 2 Association of BMI with wheezing and asthma. ORs were multivariable adjusted for age, sex, familial predisposition for asthma, smoking status, cumulative tobacco consumption, education, annual household income, physical activity in leisure time and during work, and dietary intakes, including fast food, fruits and vegetables. $\mathrm{p}$ Values for trend were across ordered groups excluding participants with $\mathrm{BMI}<18.5 \mathrm{~kg} / \mathrm{m}^{2}$. BMl, body mass index.

$1.24)$ and 1.16 (1.09 to 1.23 ) for allele score $7-10$ ( $\mathrm{p}$ for trend $3 \times 10^{-10}$ and $\left.1 \times 10^{-6}\right)$. Corresponding ORs for any asthma and for any asthma without wheezing were $1.02(0.95$ to 1.10$)$ and 1.02 (0.91 to 1.14$), 1.05$ (0.97 to 1.13$)$ and $0.92(0.82$ to $1.04)$, and $1.06(0.97$ to 1.15$)$ and 0.90 (0.79 to 1.01 ) ( $\mathrm{p}$ for trend 0.13 and 0.03$)$. A similar pattern was observed for the individual genotypes (FTO, MC4R, TMEM18, GNPDA2 and $B D N F$ ) (see online supplementary figure S5). There were no evidence of sex differences in risk of wheezing and asthma according to allele score (see online supplementary figure S7).

\section{BMI and risk of wheezing and asthma: observational versus genetic estimates}

Genetically determined high BMI was associated with high risk of wheezing, but not with high risk of asthma (figure 4). Genetically determined ORs per unit higher BMI were 1.22 (95\% CI 1.15 to 1.31 ) for wheezing, 1.18 (1.10 to 1.27 ) for wheezing without asthma, 1.08 (0.98 to 1.19$)$ for any asthma and 0.85 (0.73 to 0.99) for any asthma without wheezing.
Corresponding observational determined ORs per unit higher BMI were 1.09 (1.09 to 1.10$), 1.09$ (1.08 to 1.09$)$, 1.03 (1.03 to 1.04 ) and 0.99 (0.98 to 1.00$)$, respectively.

\section{Sensitivity analyses}

In analyses stratified according to smoking status, results were similar (compare figure 4 and online supplementary figure S8). However, the risk of self-reported asthma was slightly higher in ever-smokers compared with never-smokers ( $p$ for interaction $=0.04$ ). In analyses stratified according to age, results were also similar, perhaps with attenuated association in younger compared with older individuals (compare figure 4 and online supplementary figure S9). Investigating risk of hospital contacts with asthma prospectively, with and without wheezing at baseline, results were similar (see online supplementary figure S10). Adjusting observational analyses for BMI allele score gave similar results, and no interaction between BMI and BMI allele score was present (see online supplementary figure S11). Finally, observationally and genetically determined high BMI was 


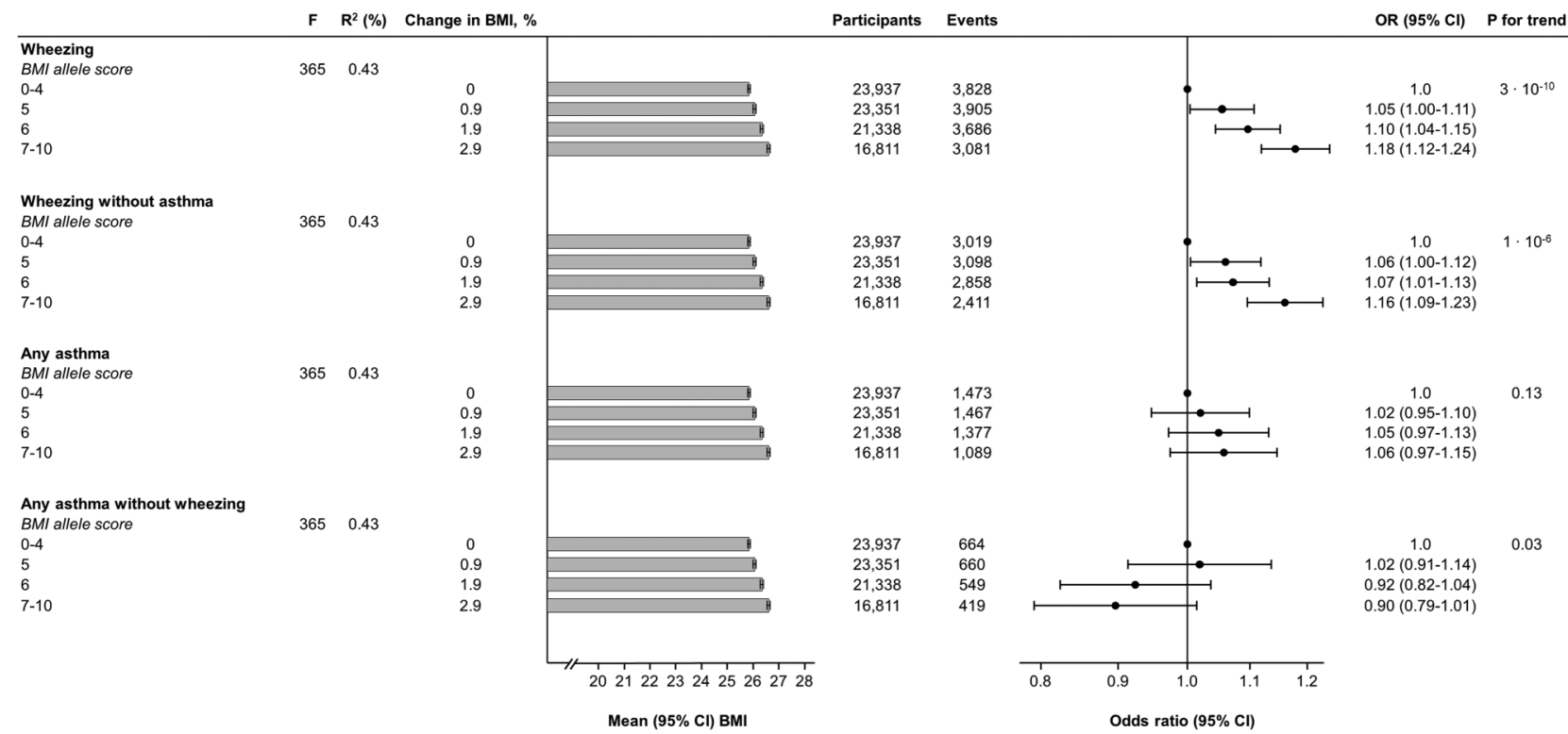

Figure 3 Association of BMI allele score with BMI and with wheezing and asthma. BMI allele score was created using the genotypes FTO (rs9939609), MC4R (rs17782313), TMEM18 (rs6548238), GNPDA2 (rs10938397) and BDNF (rs10767664). Association between BMI allele score and BMI was adjusted for age and sex. ORs were adjusted for age and sex. Number of individuals for the different outcomes differs slightly due to availability of data. BMI, body mass index; $\mathrm{F}$, statistical strength of BMI allele score as an instrument for $\mathrm{BMI} ; \mathrm{R}^{2}$, measure of explained variation in BMI by BMI allele score.

associated with high risk of having asthma and wheezing combined (compare figure 4 and online supplementary figure S12).

\section{DISCUSSION}

Among 85437 adults from the general population, we found that high BMI was associated with high risk of wheezing without asthma, but not with high risk of asthma without wheezing (figure 5). These are novel findings using novel techniques.
Mechanistically, the present findings possibly can be explained in a simple and straightforward manner: obesity causes reductions in lung and chest wall compliance (increased stiffness) by the presence of excess adipose tissue on the chest wall, on the abdomen, as well as intra-abdominally. ${ }^{24}$ In other words, because of excess fat deposited on all borders of the lungs, it becomes very difficult for obese people to breathe normally, which results in airway compression leading to frequent

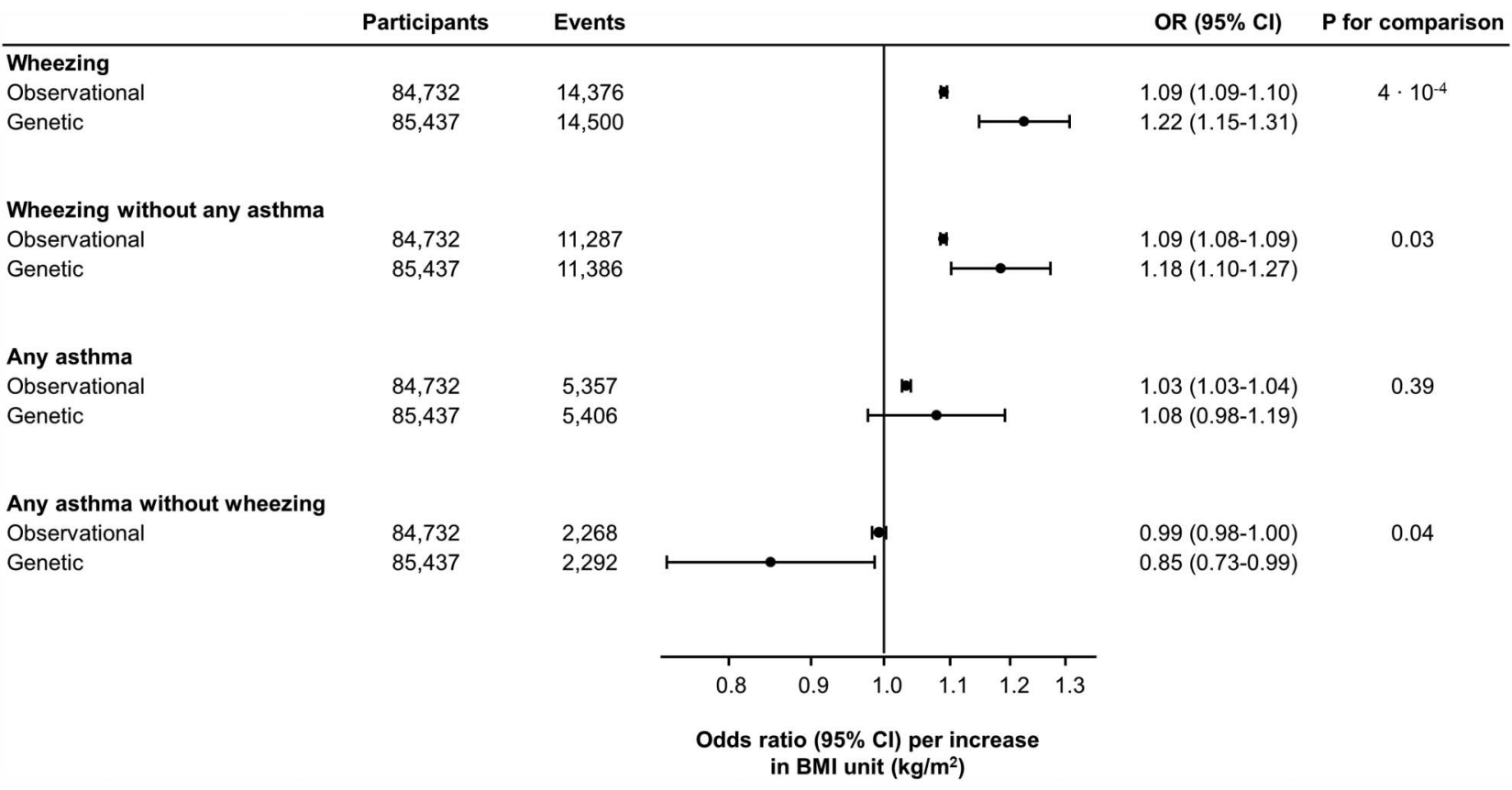

Figure 4 Association of genetic and observational determined BMI with wheezing and asthma. ORs from the observational estimates included only participants with BMI $\geq 18.5 \mathrm{~kg} / \mathrm{m}^{2}$, and were multivariable adjusted for age, sex, familial predisposition for asthma, smoking status, cumulative tobacco consumption, education, annual household income, physical activity in leisure time and during work, and dietary intakes, including fast food, fruits and vegetables. ORs for genetic analyses were obtained from the instrumental variable analyses. $p$ Values for comparison were obtained with the Hausman specification test. BMI, body mass index. 


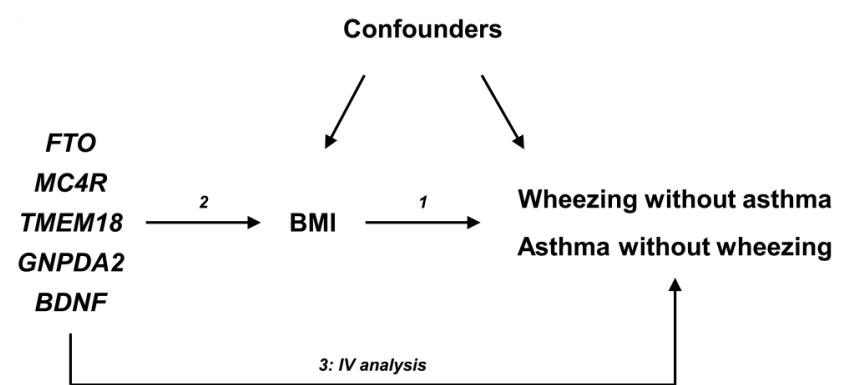

OR per increase in BMI unit $\left(\mathrm{kg} / \mathrm{m}^{2}\right)\left\{\begin{array}{l}\text { wheezing without asthma } 1.18(95 \% \mathrm{Cl}: 1.10-1.27) \\ \text { asthma without wheezing } 0.85(95 \% \mathrm{Cl}: 0.73-0.99)\end{array}\right.$

Figure 5 Mendelian randomisation design in a DAG diagram including main results. (1) The association of BMI with wheezing without asthma and with asthma without wheezing could be influenced by confounding and/or reverse causation, limitations that conventional observational studies have; (2) However, by using the genetic variants, FTO, MC4R, TMEM18, GNPDA2 and BDNF, that specifically are associated with lifelong high BMI, a Mendelian randomisation study can be conducted; (3) In a Mendelian randomisation study, the FTO, MC4R, TMEM18, GNPDA2 and BDNF are used as proxies of $B M I$ in an instrumental variable analysis, investigating the association with wheezing without asthma and with asthma without wheezing by avoiding confounding, as the genetic variants only can be associated through BMI following Mendelian inheritance, and reverse causation, as the genetic variants are present at birth. BMI, body mass index; DAG, direct acyclic graph; IV, instrumental variable.

episodes of wheezing. ${ }^{10} 17$ This symptom, however, need not necessarily be an expression of asthmatic airways inflammation.

Previous findings in support of our observations suggest that obesity is associated observationally with increased risk of asthma in some, ${ }^{1-7}$ 9-13 but not in all studies. ${ }^{3}$ 14-16 Importantly, previous studies did not explore whether the asthma association could be explained by wheezing, including a recent Mendelian randomisation study in children. ${ }^{25}$ Also, intervention studies with weight loss were associated with reduced need for asthma medication and improvement of respiratory symptoms in obese individuals with asthma. ${ }^{8}$ However, although weight loss may be beneficial for obese individuals with asthma, this does not necessarily imply that obesity is a causal risk factor for asthma. Indeed, obesity has been shown not to be related to airflow limitation ${ }^{26}$ and findings regarding airway hyper-responsiveness have been inconclusive, ${ }^{27}$ both included in the diagnosis of asthma. ${ }^{28}$ Overdiagnosis of asthma in adults is a well known problem. ${ }^{29}$ Importantly, obese individuals seem more prone to be misdiagnosed with asthma compared with normal weight individuals. ${ }^{30} 31$ Thus, it is likely that overdiagnosis of asthma because of wheezing among obese individuals is an explanation for previous findings of an association between obesity and asthma, in line with findings in the present study. The fact that anti-inflammatory asthma treatment in obese individuals works poorly is also in keeping with the possibility of overdiagnosis of asthma in obesity. ${ }^{32}$ It is also puzzling that the observational association between BMI and asthma were driven by women and did not exist for men; a plausible explanation may be that women seek their doctors more often as opposed to men, thereby, tend to be more often overdiagnosed with asthma. By contrast, the corresponding genetic association did not exist for either men or women.

Recently, in another Mendelian randomisation study, obesity was observed to be associated with childhood asthma. ${ }^{25}$ However, in that study wheezing was included in the definition of asthma, and the study thus did not address whether asthma could be misdiagnosed based on wheezing in obese children. Another explanation could be that asthma in childhood compared with in adulthood may be a different phenotype.

Potential limitations in Mendelian randomisation studies include population stratification, genetic pleiotropy and linkage disequilibrium. ${ }^{18}{ }^{19}$ However, as we had an ethnically homogenous population, the complicating effects of population stratification are likely to have been avoided. Although there seems to be genetic pleiotropy or linkage disequilibrium between genetic variants associated with obesity and asthma, ${ }^{33}$ by using five different genetic variants, which are independently associated with high BMI via different pathways, genetic pleiotropy and linkage disequilibrium are likely to have been avoided, since results were similar when using allele score or the individual genotypes. However, we cannot exclude that the allele score or the individual genotypes are associated with unmeasured confounders. Another potential limitation of our study was that the diagnosis of asthma was not defined according to the presence of reversible or variable airflow limitation and/or airway hyperresponsiveness ${ }^{28}$; however, this is not a feasible approach in large-scale population-based studies. Importantly, we used a definition of asthma which previously has been applied in numerous observational studies that also found an association between obesity and asthma. Furthermore, self-reported asthma has been evaluated rigorously before and displays high specificity and sensitivity, ${ }^{34} 35$ compared with airway hyper-responsiveness which only displays high specificity but low sensitivity. ${ }^{36}$ Also, we included hospital contacts with asthma and receiving medication for asthma as additional asthma definitions, which showed similar associations with obesity as that observed for selfreported asthma. Although we had the opportunity to investigate different definitions of asthma, it is important to acknowledge that lack of power could be an explanation for not observing an association between obesity and asthma. However, the fact that we by using the same population using the same observational BMI and the same BMI allele score were able to find clear results for wheezing without asthma argue against this possibility. Lastly, we were unable to differentiate between mild and severe asthma. However, it could be argued that selfreported asthma would have a higher proportion of milder cases of asthma compared with receiving medication for asthma or having a hospital contact with asthma, and when these end points were analysed separately, the results were similar, suggesting that the findings apply to mild asthma and severe asthma.

Strengths of the present study include a large population sample with large number of individuals experiencing wheezing and many individuals with asthma. Another strength is an objective measurement of weight and height in contrast to some previous studies which used self-reported values. ${ }^{1} 3 \quad 5 \quad 7 \quad 9-11 \quad 13$ Finally, we did not lose track of even a single person from 1977 through April 2013.

In conclusion, high BMI was associated with high risk of wheezing without asthma, but not with high risk of asthma without wheezing. These are novel observations with the potential to change clinical practice: in the future, doctors should be hesitant to prescribe anti-inflammatory asthma medication to obese individuals only because they wheeze.

\footnotetext{
Author affiliations

${ }^{1}$ Department of Internal Medicine, Section of Respiratory Medicine, Herlev and Gentofte Hospital, Copenhagen University Hospital, Herlev, Denmark

${ }^{2}$ Department of Public Health, Section of Social Medicine, University of Copenhagen, Copenhagen, Denmark

${ }^{3}$ The Copenhagen General Population Study, Herlev and Gentofte Hospital, Copenhagen University Hospital, Herlev, Denmark
} 
${ }^{4}$ Faculty of Health and Medical Sciences, University of Copenhagen, Copenhagen, Denmark

${ }^{5}$ Department of Clinical Biochemistry, Herlev and Gentofte Hospital, Copenhagen University Hospital, Herlev, Denmark

${ }^{6}$ Medical Unit, Respiratory Section, Hvidovre Hospital, Copenhagen University Hospital, Hvidovre, Denmark

Contributors YC and SA had full access to all of the data in the study and take responsibility for the integrity of the data and the accuracy of the data analyses. Study concept and design: YÇ, SA, PL and BGN. Acquisition, analyses or interpretation of data: $Y C$, SA, PL and BGN. Drafting of the manuscript: $Y C$. Critical revision of the manuscript for important intellectual content: $Y C,, S A, P L$ and $B G N$. Statistical analyses: $Y C$ and SA. Obtained funding: PL and BGN. Administrative, technical or material support: BGN. Study supervision: BGN.

Funding The Danish Lung Association, the Danish Cancer Society, Department of Clinical Biochemistry and Department of Internal Medicine, Herlev and Gentofte Hospital, Copenhagen University Hospital, and Department of Public Health, University of Copenhagen.

Competing interests $Y C$ reports personal fees from Boehringer Ingelheim outside the submitted work. PL reports grants and personal fees from Almirall, GSK and Boehringer Ingelheim, personal fees from Astra Zeneca, Novartis, ycomed, Pfizer and Mundipharma, outside the submitted work. SA and BGN has no completing interest to disclose.

Patient consent Obtained.

Ethics approval Herlev and Gentofte Hospital and a Danish ethical committee.

Provenance and peer review Not commissioned; externally peer reviewed.

\section{REFERENCES}

1 Beuther DA, Sutherland ER. Overweight, obesity, and incident asthma: a meta-analysis of prospective epidemiologic studies. Am J Respir Crit Care Med 2007; 175:661-6.

2 Beckett WS, Jacobs DR Jr, Yu X, et al. Asthma is associated with weight gain in females but not males, independent of physical activity. Am J Respir Crit Care Med 2001;164:2045-50.

3 Chen Y, Rennie D, Cormier Y, et al. Sex specificity of asthma associated with objectively measured body mass index and waist circumference: the Humboldt study. Chest 2005;128:3048-54.

4 Kronander UN, Falkenberg M, Zetterström O. Prevalence and incidence of asthma related to waist circumference and BMI in a Swedish community sample. Respir Med 2004;98:1108-16.

5 Von Behren J, Lipsett M, Horn-Ross PL, et al. Obesity, waist size and prevalence of current asthma in the California Teachers Study cohort. Thorax 2009;64:889-93.

6 Brumpton B, Langhammer A, Romundstad P, et al. General and abdominal obesity and incident asthma in adults: the HUNT study. Eur Respir J 2013:41:323-9.

7 Coogan PF, Palmer JR, O'Connor GT, et al. Body mass index and asthma incidence in the Black Women's Health Study. J Allergy Clin Immunol 2009;123:89-95.

8 Eneli IU, Skybo T, Camargo CA Jr. Weight loss and asthma: a systematic review. Thorax 2008:63:671-6.

9 Ford ES. The epidemiology of obesity and asthma. J Allergy Clin Immunol 2005;115:897-909.

10 Gunnbjörnsdóttir MI, Omenaas E, Gíslason T, et al. Obesity and nocturnal gastro-oesophageal reflux are related to onset of asthma and respiratory symptoms. Eur Respir J 2004;24:116-21.

11 Hjellvik V, Tverdal A, Furu K. Body mass index as predictor for asthma: a cohort study of 118,723 males and females. Eur Respir J 2010;35:1235-42.

12 Rönmark E, Andersson C, Nyström L, et al. Obesity increases the risk of incident asthma among adults. Eur Respir J 2005;25:282-8.
13 Uddenfeldt M, Janson C, Lampa $\mathrm{E}$, et al. High BMI is related to higher incidence of asthma, while a fish and fruit diet is related to a lower-results from a long-term follow-up study of three age groups in Sweden. Respir Med 2010;104:972-80.

14 Barranco P, Garcia-Rio F, Olivares J, et al. Asthma diagnosis is not associated with obesity in a population of adults from Madrid. J Investig Allergol Clin Immunol 2011;21:540-5.

15 Chinn S, Downs SH, Anto JM, et al. Incidence of asthma and net change in symptoms in relation to changes in obesity. Eur Respir J 2006:28:763-71.

16 Stanley AH, Demissie K, Rhoads GG. Asthma development with obesity exposure: observations from the cohort of the National Health and Nutrition Evaluation Survey Epidemiologic Follow-up Study (NHEFS). J Asthma 2005;42:97-9.

17 Schachter LM, Salome CM, Peat JK, et al. Obesity is a risk for asthma and wheeze but not airway hyperresponsiveness. Thorax 2001;56:4-8.

18 Smith GD, Ebrahim S. 'Mendelian randomization': can genetic epidemiology contribute to understanding environmental determinants of disease? Int J Epidemiol 2003;32:1-22.

19 Lawlor DA, Harbord RM, Sterne JA, et al. Mendelian randomization: using genes as instruments for making causal inferences in epidemiology. Stat Med 2008;27:1133-63.

20 Locke AE, Kahali B, Berndt SI, et al. Genetic studies of body mass index yield new insights for obesity biology. Nature 2015;518:197-206.

21 Nordestgaard BG, Palmer TM, Benn M, et al. The effect of elevated body mass index on ischemic heart disease risk: causal estimates from a Mendelian randomisation approach. PLoS Med 2012;9:e1001212.

22 [No authors listed]. Obesity: preventing and managing the global epidemic. Report of a WHO consultation. World Health Organ Tech Rep Ser 2000;894:i-xii, 1-253.

23 Palmer TM, Sterne JA, Harbord RM, et al. Instrumental variable estimation of causal risk ratios and causal odds ratios in Mendelian randomization analyses. Am J Epidemiol 2011;173:1392-403.

24 O'Donnell DE, Ciavaglia CE, Neder JA. When obesity and chronic obstructive pulmonary disease collide. Physiological and clinical consequences. Ann Am Thorac Soc 2014;11:635-44.

25 Granell R, Henderson AJ, Evans DM, et al. Effects of BMI, fat mass, and lean mass on asthma in childhood: a Mendelian randomization study. PLoS Med 2014;11: e1001669.

26 Sin DD, Jones RL, Man SF. Obesity is a risk factor for dyspnea but not for airflow obstruction. Arch Intern Med 2002;162:1477-81.

27 Shore SA. Obesity, airway hyperresponsiveness, and inflammation. J App/ Physiol (1985) 2010;108:735-43.

28 Global Strategy for Asthma Management and Prevention. Global Initiative for Asthma (GINA). http://ginaasthma.org/documents/4 (accessed 26 Aug 2014).

29 Aaron SD, Vandemheen KL, Boulet LP, et al. Overdiagnosis of asthma in obese and nonobese adults. CMAJ 2008;179:1121-31.

30 Pakhale S, Doucette $S$, Vandemheen $\mathrm{K}$, et al. A comparison of obese and nonobese people with asthma: exploring an asthma-obesity interaction. Chest 2010;137:1316-23.

31 Scott S, Currie J, Albert P, et al. Risk of misdiagnosis, health-related quality of life, and $\mathrm{BMI}$ in patients who are overweight with doctor-diagnosed asthma. Chest 2012;141:616-24.

32 Peters-Golden M, Swern A, Bird SS, et al. Influence of body mass index on the response to asthma controller agents. Eur Respir J 2006;27:495-503.

33 Hallstrand TS, Fischer ME, Wurfel MM, et al. Genetic pleiotropy between asthma and obesity in a community-based sample of twins. J Allergy Clin Immunol 2005; 116:1235-41.

34 de Marco R, Cerveri I, Bugiani M, et al. An undetected burden of asthma in Italy: the relationship between clinical and epidemiological diagnosis of asthma. Eur Respir J 1998;11:599-605.

35 Torén K, Brisman J, Järvholm B. Asthma and asthma-like symptoms in adults assessed by questionnaires. A literature review. Chest 1993;104:600-8.

36 Peat JK, Toelle BG, Marks GB, et al. Continuing the debate about measuring asthma in population studies. Thorax 2001;56:406-11. 